\title{
Perbandingan Efektivitas $T$-spring Berdimensi Kawat 0,5 mm dan 0,6 mm terhadap Koreksi Gigi Malposisi Individual (Kajian pada Typodont)
}

\author{
Ni Luh S. Desyani, Pritartha S. Anindita, Michael A. Leman
}

\author{
Program Studi Pendidikan Dokter Gigi Fakultas Kedokteran Universitas Sam Ratulangi, \\ Manado, Indonesia \\ Email: srinyadhesyani@gmail.com
}

\begin{abstract}
Malocclusion can trigger various health problems in the oral cavity. The simplest form of malocclusion is individual dental malposition which can be corrected by removable orthodontic appliances with active components T-springs made of $0.5 \mathrm{~mm}$ or $0.6 \mathrm{~mm}$ wire dimensions. This study was aimed to compare the effectiveness of the T-spring with wire dimensions of $0.5 \mathrm{~mm}$ and of $0.6 \mathrm{~mm}$ on the correction of individual dental malpositions. This was a pre-experimental study using a one-shot case study design. Study samples were divided into two groups, T-spring with wire dimensions of $0.5 \mathrm{~mm}$ and of $0.6 \mathrm{~mm}$ on removable orthodontic appliances attached to typodonts. The samples were activated, and the typodonts were immersed in warm water until the individual tooth malpositions were corrected. The number of activations and the average tooth movement each time the activation were calculated and analyzed. The numbers of T-spring activations with $0.5 \mathrm{~mm}$ and $0.6 \mathrm{~mm}$ wire dimensions were analyzed with the Mann-Whitney test that showed a p-value of $0.042(\mathrm{p}<0.05)$. The data of the mean tooth movement each time the Tspring was activated were analyzed with the independent sample t-test that obtained a $p$ value of 0.016 ( $\mathrm{p}<0.05)$. In conclusion, the T-spring with wire dimension of $0.5 \mathrm{~mm}$ is more effective in correcting individual dental malpositions than the T-Spring with wire dimensions of $0.6 \mathrm{~mm}$.
\end{abstract}

Keywords: tooth malposition; removable orthodontics; effectiveness of T-spring

\begin{abstract}
Abstrak: Maloklusi dapat memicu berbagai masalah kesehatan pada rongga mulut. Bentuk sederhana dari maloklusi yaitu malposisi gigi individual yang dapat dikoreksi dengan alat ortodonti lepasan dengan komponen aktif pegas $\mathrm{T}$ ( $T$-spring) yang terbuat dari kawat berdimensi $0,5 \mathrm{~mm}$ atau $0,6 \mathrm{~mm}$. Penelitian ini bertujuan untuk mengetahui perbandingan efektivitas $T$-spring dengan dimensi kawat $0,5 \mathrm{~mm}$ dan $0,6 \mathrm{~mm}$ terhadap koreksi malposisi gigi individual. Jenis penelitian yaitu preexperimental dengan menggunakan one-shot case study design. Sampel penelitian dibagi menjadi dua kelompok yaitu $T$-spring dengan dimensi kawat $0,5 \mathrm{~mm}$ dan $0,6 \mathrm{~mm}$ pada alat ortodonti lepasan yang dipasang ke typodont. Sampel diaktivasi dan typodont direndam dalam air hangat hingga malposisi gigi individual terkoreksi. Jumlah aktivasi serta rerata jarak perpindahan gigi setiap kali $T$ spring diaktivasi dihitung dan dianalisis. Data jumlah aktivasi $T$-spring dimensi kawat $0,5 \mathrm{~mm}$ dan $0,6 \mathrm{~mm}$ dianalisis menggunakan uji Mann Whitney yang menunjukkan nilai $\mathrm{p}=0,042(\mathrm{p}<0,05)$. Data rerata jarak perpindahan gigi setiap kali $T$-spring diaktivasi dianalisis menggunakan uji independent sample t-test dan memperoleh nilai $\mathrm{p}=0,016(\mathrm{p}<0,05)$. Simpulan penelitian ini ialah $T$-spring dengan dimensi kawat $0,5 \mathrm{~mm}$ lebih efektif dalam mengoreksi malposisi gigi individual dibandingkan $T$ spring dengan dimensi kawat $0,6 \mathrm{~mm}$.
\end{abstract}

Kata kunci: malposisi gigi; ortodonti lepasan; efektivitas $T$-spring

\section{PENDAHULUAN}

Prevalensi kelainan susunan gigi atau maloklusi di Indonesia masih tinggi yaitu sekitar $80 \%$ dan menjadi salah satu perma- salahan kesehatan gigi dan mulut yang sering dijumpai setelah karies dan penyakit periodontal. ${ }^{1}$ Maloklusi adalah suatu kondisi yang menyimpang dari oklusi normal 
atau suatu kondisi yang menyimpang dari relasi normal suatu gigi terhadap gigi yang lainnya, sehingga mengganggu atau menimbulkan potensi ancaman terhadap perkembangan dan pemeliharaan jaringan normal, fungsi efektif, bahkan masalah perilaku psikologis. $^{2}$ Maloklusi dapat menimbulkan ketidakpercayaan diri akibat kondisi gigi yang tidak teratur. Beberapa faktor etiologi maloklusi di antaranya ialah faktor keturunan, gangguan pertumbuhan, trauma, keadaan fisik, kebiasaan buruk, penyakit sistemik, penyakit lokal, dan malnutrisi. ${ }^{3}$

Maloklusi dapat dibagi menjadi tiga jenis yaitu malposisi gigi, hubungan yang tidak harmonis dari lengkung gigi atau segmen dentoalveolar, dan hubungan yang tidak harmonis dari skeletal. ${ }^{3}$ Malposisi dapat terjadi secara berkelompok yang melibatkan beberapa gigi maupun individual. Malposisi gigi individual merupakan kelainan posisi dari masing-masing gigi dalam lengkungnya dan merupakan bentuk maloklusi sederhana, biasanya berupa inklinasi abnormal (tipping), rotasi, dan transposisi. ${ }^{3}$ Malposisi gigi individual dapat dikoreksi dengan alat ortodonti baik cekap maupun lepasan.

Alat ortodonti lepasan merupakan alat ortodonti yang pemakaiannya dapat dipasang dan dilepas sendiri oleh pasien. Saat ini alat ortodonti lepasan sudah mulai ditinggalkan. Hal ini dikarenakan alat ortodonti cekat lebih diminati oleh pasien selain digunakan untuk memperbaiki posisi gigi, juga menjadi trend di kalangan anak muda untuk keperluan estetika. Namun demikian alat ortodonti lepasan dinilai masih efektif dalam perawatan ortodonti. ${ }^{4,5}$

Salah satu komponen aktif yang digunakan dalam alat ortodonti lepasan yaitu pegas $\mathrm{T}$ (T-spring). T-spring merupakan pegas palatal yang terdiri dari lengan berbentuk $T$ loop, lengan retentive, dan retentive tag. ${ }^{6,7} T$-spring digunakan untuk menggerakkan gigi individu ke labial maupun ke arah bukal dan dipakai pada gigi posterior. Pergerakan gigi tersebut terlihat setelah adanya trauma atau tekanan yang diberikan oleh $T$-spring dalam kondisi patologik tertentu. Pada pergerakan gigi ini, respon jaringan periodontal dan tulang terhadap tekanan sangat berpengaruh. ${ }^{3}$

Untuk dapat menggerakan gigi akar tunggal diperlukan kekuatan sebesar 25-40 gr/mm. Kekuatan kurang dari dari 25 $\mathrm{gr} / \mathrm{mm}$ tidak memungkinkan terjadinya pergerakan gigi dalam waktu yang optimal, sedangkan apabila kekuatan lebih dari 40 $\mathrm{gr} / \mathrm{mm}$ mengakibatkan kerusakan jaringan periodontal dan kemungkinan pergerakan gigi tertunda. ${ }^{8}$ Dimensi kawat lebih kecil menghasilkan kelentingan yang lebih besar, dan daya yang lebih kecil sehingga tidak merusak jaringan periodontal dan tidak mengakibatkan timbulnya rasa sakit yang berlebih. Stabilisasi aktif juga menyiratkan ambang batas untuk gaya ortodontik, karena gaya di bawah tingkat stabilisasi diperkirakan tidak akan efektif. ${ }^{3}$

Berdasarkan latar belakang ini maka penulis tertarik untuk melakukan penelitian mengenai perbandingan efektivitas $T$-spring dengan dimensi kawat $0,5 \mathrm{~mm}$ dan $0,6 \mathrm{~mm}$ terhadap koreksi gigi malposisi individual.

\section{METODE PENELITIAN}

Penelitian ini dilaksanakan pada bulan Juni 2021 bertempat di Laboratorium Program Studi Pendidikan Dokter Gigi, Universitas Sam Ratulangi Manado. Jenis penelitian ini yaitu pre-experimental dengan rancangan one-shot case study design. Pada penelitian ini terdapat dua kelompok perlakuan yaitu kelompok $T$-spring dengan dimensi kawat $0,5 \mathrm{~mm}$ dan yang dengan dimensi kawat $0,6 \mathrm{~mm}$. Tujuan penelitian ini untuk mengevaluasi dan menilai efektifitas T-spring ditinjau dari jumlah aktivasi dan rerata jarak perpindahan gigi setiap kali $T$ spring diaktivasi. Populasi penelitian yaitu alat ortodonti lepasan dengan dua buah $T$ spring yang dipasang pada typodont rahang atas. Pengambilan sampel menggunakan teknik simple random sampling. Terdapat dua kelompok sampel yaitu 16 buah $T$ spring dengan dimensi kawat $0,5 \mathrm{~mm}$ dan 16 buah $T$-spring dengan dimensi kawat 0,6 $\mathrm{mm}$. Data primer diambil dengan menggunakan teknik observasi.

Typodont disiapkan terlebih dahulu dengan cara direndam dalam air hangat 
bersuhu $60^{\circ} \mathrm{C}$ hingga malam merah melunak kemudian gigi premolar satu rahang atas di regio kanan dan kiri pada typodont diatur pada posisi palatoversi sebesar $5 \mathrm{~mm}$. Alat ortodonti lepasan dengan $T$-spring yang telah diaktivasi sebesar $1 \mathrm{~mm}$ dipasang pada typodont dan direndam dalam air hangat dengan suhu $50^{\circ} \mathrm{C}$ selama 5 menit. Untuk menghindari malam merah meleleh, typodont diangkat dari perendaman dan diberi jeda selama 5 menit pada suhu ruangan, untuk selanjutnya dilakukan perendaman kedua dalam suhu yang sama selama 5 menit. Typodont kemudian diangkat dari perendaman dan dicatat jarak perpindahan gigi yang terjadi. Proses aktivasi dan perendaman dilakukan berulang kali sampai gigi palatoversi $5 \mathrm{~mm}$ terkoreksi dan mencapai lengkung ideal.

Analisis data menggunakan program aplikasi komputer SPSS (Statistical Product and Service Solutions) windows 13. Uji normalitas data dilakukan dengan menggunakan uji Saphiro-Wilk. Uji homogenitas dilakukan dengan menggunakan uji Levene untuk mengetahui data tersebut berasal dari populasi yang memiliki varians sama atau tidak. Berdasarkan hasil uji Saphiro-Wilk data jumlah aktivasi $T$-spring terdistribusi tidak normal, maka dilanjutkan dengan uji Mann Whitney. Data rerata jarak perpindahan gigi setiap kali $T$-spring diaktivasi terdistribusi normal, maka dilanjutkan dengan uji independent sample t-test.

\section{HASIL PENELITIAN}

Berdasarkan penelitian yang telah dilakukan, diperoleh jumlah aktivasi yang diperlukan oleh $T$-spring hingga gigi mencapai lengkung ideal dan nilai rerata jarak perpindahan gigi setiap kali $T$-spring diaktivasi.

Tabel 1 memperlihatkan data jumlah aktivasi yang dibutuhkan oleh T-spring. Kelompok $T$-spring dengan dimensi kawat $0,5 \mathrm{~mm}$ sebagian besar diaktivasi sebanyak 5 kali (8 sampel), sedangkan untuk kelompok $T$-spring dengan dimensi kawat $0,6 \mathrm{~mm}$ sebagian besar diaktivasi sebanyak 6 kali ( 8 sampel).
Tabel 1. Data jumlah aktivasi $T$-spring

\begin{tabular}{|c|c|c|}
\hline \multirow{2}{*}{$\begin{array}{c}\text { Jumlah } \\
\text { aktivasi } \\
\text { (Pengulangan) }\end{array}$} & \multicolumn{2}{|c|}{$\begin{array}{c}\text { Jumlah sampel } \\
(T \text {-spring })\end{array}$} \\
\hline & $\begin{array}{c}\text { Dimensi } \\
\text { kawat } \\
0,5 \mathrm{~mm}\end{array}$ & $\begin{array}{c}\text { Dimensi } \\
\text { kawat } \\
0,6 \mathrm{~mm}\end{array}$ \\
\hline 4 & 1 & 0 \\
\hline 5 & 8 & 4 \\
\hline 6 & 6 & 8 \\
\hline 7 & 1 & 4 \\
\hline
\end{tabular}

Tabel 2 memperlihatkan data rerata jarak perpindahan gigi setiap kali T-spring diaktivasi. Terlihat bahwa gigi yang dikoreksi pada kelompok $T$-spring dengan dimensi kawat $0,5 \mathrm{~mm}$ paling banyak mengalami perpindahan sebesar 0,80-0,90 mm, sedangkan untuk kelompok $T$-spring dengan kawat berdimensi $0,6 \mathrm{~mm}$ paling banyak mengalami perpindahan sebesar $0,70-0,80 \mathrm{~mm}$.

Tabel 2. Data rerata perpindahan gigi setiap kali diaktivasi

\begin{tabular}{lcc}
\hline Rerata jarak & \multicolumn{2}{c}{ Jumlah sampel } \\
perpindahan & $T$-spring & $T$-spring \\
gigi setiap kali & $0,5 \mathrm{~mm}$ & $0,6 \mathrm{~mm}$ \\
$\begin{array}{l}\text { T-spring } \\
\text { diaktivasi (mm) }\end{array}$ & & \\
\hline $0,60-0,70$ & 2 & 6 \\
$0,70-0,80$ & 5 & 7 \\
$0,80-0,90$ & 7 & 3 \\
$0,90-1,00$ & 2 & 0 \\
\hline
\end{tabular}

Tabel 3 memperlihatkan hasil uji normalitas dengan metode Saphiro-Wilk untuk data jumlah aktivasi T-spring pada tiap kelompok. Nilai signifikansi data jumlah aktivasi kawat untuk kelompok $T$-spring berdimensi kawat $0,5 \mathrm{~mm}$ yaitu $\mathrm{p}=0,013$ dan untuk kawat berdimensi $0,6 \mathrm{~mm}$ senilai $\mathrm{p}=0,005(\mathrm{p}<0,05)$ yang menunjukkan data kedua kelompok terdistribusi tidak normal. Hasil uji Saphiro-Wilk pada data rerata jarak perpindahan gigi setiap kali $T$-spring diaktivasi memperoleh nilai signifikansi untuk kelompok $T$-spring dengan dimensi kawat $0,5 \mathrm{~mm}$ yaitu $\mathrm{p}=0,630$ dan kelompok dimensi kawat $0,6 \mathrm{~mm}$ sebesar $\mathrm{p}=0,677 \quad(\mathrm{p}>0,05)$ sehingga data rerata jarak perpindahan gigi setiap kali $T$-spring diaktivasi untuk kedua kelompok dinyatakan terdistribusi normal. 
Tabel 4 memperlihatkan hasil uji homogenitas data jumlah aktivasi $T$-spring dan data rerata jarak perpindahan gigi setiap kali $T$-spring diaktivasi. Uji homogenitas Levene digunakan untuk mencari tahu apakah dua kelompok penelitian berasal dari populasi yang memiliki varians sama dengan perolehan nilai $\mathrm{p}=0,458$ untuk data jumlah aktivasi $T$-spring dan nilai $\mathrm{p}=0,640$ untuk data rerata jarak perpindahan gigi setiap kali $T$-spring diaktivasi yang menunjukkan kedua data tersebut homogen.

Berdasarkan hasil uji normalitas diketahui bahwa data jumlah aktivasi $T$-spring tidak terdistribusi normal, sedangkan untuk data rerata jarak perpindahan gigi setiap kali $T$-spring diaktivasi terdistribusi normal, maka digunakan uji yang berbeda.

Tabel 5 memperlihatkan hasil uji Mann Whitney pada data jumlah aktivasi dengan nilai $\mathrm{p}=0,042$ yang berarti terdapat perbedaan bermakna antara efektivitas T-spring dimensi kawat $0,5 \mathrm{~mm}$ dengan dimensi kawat 0,6 mm ditinjau dari jumlah aktivasi T-spring.

Tabel 6 memperlihatkan hasil uji independent sample t-test rerata jarak perpindahan gigi setiap kali $T$-spring diaktivasi dengan nilai $\mathrm{p}=0,016$ dan perbedaan rerata sebesar 0,067 yang berarti secara statistik terdapat perbedaan bermakna antara efektivitas $T$ spring dengan dimensi kawat 0,5 $\mathrm{mm}$ dan 0,6 $\mathrm{mm}$ ditinjau dari rerata jarak perpindahan gigi setiap kali $T$-spring diaktivasi.

Tabel 3. Hasil uji normalitas data jumlah aktivasi T-spring

\begin{tabular}{lccc}
\hline & $\begin{array}{c}\text { Dimensi } \\
\text { kawat }\end{array}$ & Nilai p & $\begin{array}{c}\text { Saphiro-Wilk } \\
\text { Interpretasi }\end{array}$ \\
\hline Jumlah aktivasi T-spring & $0,5 \mathrm{~mm}$ & 0,013 & Distribusi tidak normal \\
& $0,6 \mathrm{~mm}$ & 0,005 & Distribusi tidak normal \\
Rerata jarak perpindahan gigi & $0,5 \mathrm{~mm}$ & 0,630 & Distribusi normal \\
setiap kali T-spring diaktivasi & $0,6 \mathrm{~mm}$ & 0,677 & Distribusi normal \\
\hline
\end{tabular}

Tabel 4. Hasil uji homogenitas data

\begin{tabular}{lccc}
\hline & Levene Statistic & Nilai p & Interpretasi \\
\hline Jumlah aktivasi $T$-spring & 0.564 & 0.458 & Homogen \\
Rerata jarak perpindahan gigi setiap kali & 0.223 & 0.640 & Homogen \\
T-spring diaktivasi & & & \\
\hline
\end{tabular}

Tabel 5. Hasil uji Mann Whitney data jumlah aktivasi T-spring

\begin{tabular}{lccc}
\hline & $\begin{array}{c}\text { Median } \\
\text { (Minimum-Maksimum) }\end{array}$ & $\begin{array}{c}\text { Mean } \\
\text { Rank }\end{array}$ & Nilai p \\
\hline$T$-spring dimensi kawat $0,5 \mathrm{~mm}(\mathrm{n}=16)$ & $5(4-7)$ & 13,38 & 0,042 \\
$T$-spring dimensi kawat $0,6 \mathrm{~mm}(\mathrm{n}=16)$ & $6(5-7)$ & 19,63 & \\
\hline
\end{tabular}

Tabel 6. Hasil uji independent sample t-test data jarak perpindahan gigi setiap kali T-spring diaktivasi

\begin{tabular}{lccc}
\hline & Rerata (s.b) & $\begin{array}{c}\text { Perbedaan } \\
\text { rerata (IK95\%) }\end{array}$ & Nilai p \\
\hline$T$-spring dimensi kawat $0,5 \mathrm{~mm}(\mathrm{n}=16)$ & $0,78(0,08)$ & $0,067(0,13-0,12)$ & 0,016 \\
$T$-spring dimensi kawat $0,6 \mathrm{~mm}(\mathrm{n}=16)$ & $0,72(0,06)$ & & \\
\hline
\end{tabular}




\section{BAHASAN}

Hasil uji Mann Whitney untuk data jumlah aktivasi $T$-spring pada kedua kelompok dimensi kawat menunjukkan nilai signifikansi $\mathrm{p}=0,042$. Secara statistik terdapat perbedaan bermakna antara efektivitas $T$ spring dengan dimensi kawat 0,5 mm dan 0,6 mm ditinjau dari jumlah aktivasi $T$-spring. Kelompok $T$-spring dengan kawat berdimensi $0,5 \mathrm{~mm}$ memiliki jumlah aktivasi yang lebih sedikit dibandingkan kelompok $T$ spring dengan kawat berdimensi 0,6 $\mathrm{mm}$. Hal ini dikarenakan kawat berdimensi kecil memiliki kelentingan yang lebih besar dengan daya yang lebih kecil sehingga malposisi gigi individual dapat terkoreksi lebih cepat. Banyaknya jumlah aktivasi $T$-spring dipengaruhi oleh besar defleksi yang diberikan, besar jarak pergeseran gigi, dan gaya dorong yang dihasilkan oleh kawat itu sendiri.

Pengujian data rerata jarak perpindahan gigi setiap kali $T$-spring diaktivasi menggunakan uji statistik independent sample t-test yang menunjukkan nilai signifikansi $\mathrm{p}=0,016$ dengan perbedaan rerata atau mean difference sebesar 0,067. Dengan demikian dapat disimpulkan bahwa terdapat perbedaan bermakna antara efektivitas T-spring dengan dimensi kawat 0,5 mm dan 0,6 mm ditinjau dari rerata jarak perpindahan gigi setiap kali $T$-spring diaktivasi. Jarak perpindahan gigi pada kelompok $T$-spring dengan kawat $0,5 \mathrm{~mm}$ lebih besar dibandingkan dengan kelompok kawat berdimensi 0,6 $\mathrm{mm}$. Pergeseran gigi terlihat setelah adanya tekanan konstan yang diberikan oleh $T$ spring pada saat perendaman dalam air hangat. Tekanan ini terjadi terus menerus secara berkelanjutan dan menggerakkan gigi hingga mencapai lengkung ideal.

Kawat harus memiliki sifat defleksi yang besar tanpa adanya perubahan pada kawat tersebut, dengan kata lain memiliki kelentingan. Kawat yang memiliki kelentingan rendah dapat mengakibatkan gaya yang diberikan pada gigi tidak efektif. Kelentingan akan memberikan gaya konstan selama pergeseran gigi dan memungkinkan jarak perpindahan gigi bertambah besar. Besarnya daya lenting ditentukan oleh besarnya kawat atau luas penampang kawat, panjang kawat, dan perubahan suhu. ${ }^{9}$

Kawat dengan diameter kecil menghasilkan kelentingan yang lebih besar, namun daya yang dihasilkan lebih kecil. Kawat dengan diameter besar kelentingan yang dihasilkan lebih kecil, namun daya yang dihasilkan lebih besar. ${ }^{10}$ Daya yang terlalu besar dapat menyebabkan kerusakan pada jaringan periodontal dan dapat menghambat jaringan pembuluh darah disekitarnya sehingga dapat menyebabkan gigi tersebut mengalami nekrosis. ${ }^{11}$

Penelitian yang dilakukan oleh Muthia et al ${ }^{12}$ menjelaskan bahwa kawat berdimensi 0,5 $\mathrm{mm}$ dan 0,6 $\mathrm{mm}$ keduanya dapat digunakan untuk membuat spring. Rerata daya yang dihasilkan sampel finger spring diameter kawat $0,5 \mathrm{~mm}$ sebesar $70 \mathrm{gr} / \mathrm{mm}^{2}$, dan rerata daya yang dihasilkan oleh sampel finger spring diameter kawat 0,6 $\mathrm{mm}$ sebesar 129,6 gr/mm². Kawat dengan dimensi $0,5 \mathrm{~mm}$ dinilai memiliki efektivitas yang lebih baik karena daya yang dihasilkan lebih kecil sehingga tidak merusak jaringan periodontal dibandingkan dengan kawat yang berdimensi $0,6 \mathrm{~mm}$.

Hasil penelitian ini memperlihatkan bahwa $T$-spring dengan kawat berdimensi $0,5 \mathrm{~mm}$ memiliki jumlah aktivasi yang lebih sedikit dibandingkan dengan kawat yang berdimensi $0,6 \mathrm{~mm}$. Jarak perpindahan gigi pada kelompok kawat $0,5 \mathrm{~mm}$ lebih besar dibandingkan dengan kelompok kawat berdimensi 0,6 $\mathrm{mm}$. Hasil uji statistik mendapatkan perbedaan bermakna antara efektivitas $T$-spring dengan dimensi kawat $0,5 \mathrm{~mm}$ dan $0,6 \mathrm{~mm}$. Jumlah aktivasi yang lebih sedikit dan jarak perpindahan gigi yang besar dapat mengurangi durasi kunjungan pasien, mempersingkat waktu perawatan, dan mengurangi biaya.

\section{SIMPULAN}

$T$-spring dengan dimensi kawat $0,5 \mathrm{~mm}$ lebih efektif dalam mengoreksi malposisi gigi individual dibandingkan $T$-spring dengan dimensi kawat $0,6 \mathrm{~mm}$ ditinjau dari jumlah aktivasi $T$-spring dan rerata jarak perpindahan gigi setiap kali $T$-spring diaktivasi. 


\section{Konflik Kepentingan}

Penulis menyatakan tidak terdapat konflik kepentingan dalam studi ini.

\section{DAFTAR PUSTAKA}

1. Budiyanti EA. Pengaruh perilaku ibu dan pola keluarga pada kebiasaan menghisap jari pada anak, dikaitkan dengan status oklusi gigi sulung: studi epidemiologi pada anak TK di DKI Jakarta [Disertasi]. Jakarta: Universitas Indonesia; 2013.

2. Marya C. A Textbook of Public Health Dentistry (1st ed). New Delhi: Jaypee Brothers Medical Publishers, 2011; p. 183-4.

3. Schwarz AM. Textbook of Orthodontics (2nd ed). New Delhi: Jaypee Brothers Medical Publishers, 2007; p. 396-9.

4. Yordan B. Tingkat keberhasilan perawatan ortodontik crowding anterior dengan rotasi yang menggunakan alat removable kombinasi sederhana (The accomplishment rate of anterior crowding orthodontic treatment with rotation by using the combination of simple removable). Denta J Kedokteran Gigi. 2016;10(2):2-6.

5. Irwansyah M, Erwansyah E. Penilaian tingkat keberhasilan perawatan ortodontik dengan piranti lepasan berdasarkan indeks PAR (Assessment of success rate of orthodontic treatment using removable appliance based on PAR Index). J Dentomaxillofacial Sci. 2011;10(3):1-5.

6. Friedy L, Zararna N. Orthodontic Retainer and Removable Appliances, Principles of Design and Use (1st ed). Chichester: Wiley's Global Scientific, Technical and Medical Business with Blackwell Publishing, 2013; p. 10-15.

7. Wells W, Burnett J, Moriarty S. Advertising Principles and Practice (2nd ed). New Delhi: Jaypee Brothers Medical Publisher's, 1992; p. 309-11.

8. Rahardjo P. Peranti Ortodonti Lepasan (2nd ed). Surabaya: Pusat Penerbitan dan Percetakan Airlangga University Press, 2009; p. 9-17.

9. Yulita N, Kurniawan FKD, Wibowo D. Perbandingan suhu $37^{\circ} \mathrm{c}$ dan $45^{\circ} \mathrm{c}$ terhadap daya lenting kawat ortodonti stainless steel. Dento J Kedokteran Gigi. 2017; I(1):11-5.

10. Proffit W, Fields H, Sarver D. Contemporary Orthodontics (5th ed). North Carolina: Elsevier Inc, 2013; p. 293-7.

11. Inawati Y. Reaksi jaringan periodontal terhadap pergerakan gigi pada perawatan ortodonti. Dento J Kedokteran Gigi. 2017; $\mathrm{I}: 15-8$.

12. Muthia ID, Wibowo D, Widodo W. Perbandingan daya lenting pegas jari dengan diameter kawat 0,5 $\mathrm{mm}$ dan 0,6 $\mathrm{mm}$. Dentino J Kedokteran Gigi.2017;II(1):93-6. 